Reflexão e Ação, v 23, n. 3, 2015.

\title{
EDUCAÇÃO DE SURDOS: POLÍTICAS E PRÁTICAS
}

Existem momentos na vida onde a questão de saber se se pode pensar diferentemente do que se pensa, e perceber diferentemente do que se vê, é indispensável para continuar a olhar ou refletir (FOUCAULT, 1984, p. 13).

Adriana da Silva Thoma ${ }^{I}$

Claudio José de Oliveira

O Dossiê Temático "EDUCAÇÃO DE SURDOS: políticas e práticas” apresenta pesquisas e discussões sobre a educação de surdos, campo que nos últimos anos vem sendo regulado por leis que reconhecem direitos e por políticas que orientam práticas na área da surdez, exigindo possibilidades de se "pensar diferentemente do que se pensa e perceber diferentemente do que se vê". Tais políticas e práticas "se constituem em paradoxos contemporâneos no governamento da população surda" (LOPES e THOMA, 2012), pois "tanto festejam a diferença identitária surda quanto investem na correção/normalização dos indivíduos com surdez" (idem).

Esse cenário tem incentivado e mobilizado pesquisas e propostas que dialogam com distintas perspectivas sobre os surdos, a surdez e sua educação. Discursos de vários campos criam significados diferentes para a surdez e a educação de surdos, mas todas as atuais políticas e práticas apontam para a educação bilíngue como sendo a mais adequada para os

\footnotetext{
${ }^{1}$ Professora do Programa de Pós-Graduação em Educação da Universidade Federal do Rio Grande do Sul (UFRGS). Coordenadora do Grupo de Pesquisas SINAIS: Sujeitos, Inclusão, Narrativas, Alteridades, Identidades e Subjetividades; Pesquisadora do Grupo Interinstitucional de Pesquisa em Educação de Surdos (GIPES). Endereço: Rua Sarmento Leite, 245 - Centro Histórico, Porto Alegre - RS, Brasil. Endereço eletrônico: asthoma@terra.com.br.

${ }^{2}$ Professor Pesquisador no Programa de Pós-Graduação em Educação da Universidade de Santa Cruz do Sul UNISC. Pesquisador do Grupo de Pesquisa Identidade e Diferença na Educação (IDE/UNISC/CNPq) e Grupo de Pesquisa Interinstitucional de pesquisa em docências, pedagogias e diferenças (GIPEDI/UNISINOS/CNPq). Endereço: Av. Independência, 2293, Universitário, Santa Cruz do Sul - RS / Brasil. Endereço eletrônico: coliveir@unisc.br.
} 
alunos surdos. Porém os significados que bilíngue assume variam, pois "as diferentes significações dadas aos sujeitos surdos e a educação bilíngue estão imersas em relações de saber-poder, tendo implicações na produção de regimes de verdade" (STÜRMER e THOMA, 2015).

Com a oficialização da Língua Brasileira de Sinais (Libras) através da Lei 10.436/2002 I, vimos uma proliferação de debates e proposições sobre as condições de existência atuais da educação de surdos, mobilizados por "princípios político-ideológicos distintos" (LODI, 2013): de por um lado, a atual política de inclusão escolar do Ministério da Educação propõe a escola comum e o atendimento educacional especializado em turno oposto, o que contraria as demandas apresentadas pelo movimento surdo, cujas pautas "vêmse reconfigurando, sendo que as discussões relativas às políticas educacionais ganharam contornos de possibilidades de reafirmação de iniciativas de mobilização do povo surdo" (THOMA e KLEIN, 2010, p. 113). Na esteira, vários pesquisadores da área, que trabalham em uma perspectiva cultural da surdez, vêm apresentando resultados de pesquisas e feito problematizações que sinalizam para as escolas bilíngues como o espaço mais produtivo, que promove maiores índices de aprendizagem e que potencializam o desenvolvimento de identidades surdas culturais.

Nesse sentido, as políticas educacionais e linguísticas são temas que interessam a professores e pesquisadores da área e o objetivo desse número temático, portanto, é dar visibilidade para os conhecimentos que vem sendo produzidos na área e as problematizações que deles decorrem. Trata-se uma produção que envolve a articulação dos grupos de pesquisa SINAIS - UFRGS/CNPq e Identidade e Diferença em Educação - UNISC/CNPq e que reúne, no total, dezoito artigos organizados em duas seções: doze compõem a primeira seção, dedicada ao tema central do Dossiê, com textos que foram reunidos e organizados a partir de certas afinidades conceituais, possibilitando aos leitores aproximações e distanciamentos entre o campo dos Estudos Surdos, as políticas e práticas voltadas para a educação de sujeitos surdos em espaços escolares e não escolares. A segunda seção, por sua vez, de fluxo contínuo, traz outros seis artigos com temáticas variadas sobre o campo da educação. O resultado é o que apresentamos a seguir.

Iniciamos com uma produção de pesquisas acadêmicas sobre a inserção da disciplina Língua Brasileira de Sinais no Ensino Superior é o tema do artigo Disciplina de libras: o que as pesquisas acadêmicas dizem sobre a sua inserção no ensino superior?, de Angela Nediane dos Santos e Madalena Klein. A partir da análise de teses, dissertações, anais de eventos e 
revistas, são destacados discursos em torno da referida disciplina e problematizados os significados e efeitos produzidos por tais discursos na educação e nos currículos da referida disciplina.

Em $O$ ensino do português como segunda língua para surdos: estratégias didáticas, de Djair Lázaro de Almeida, Glaucia Ferreira Dias dos Santos e Cristina Broglia Feitosa de Lacerda, os autores descrevem e analisam estratégias pedagógicas para ensinar português para alunos surdos a partir de pressupostos teóricos da abordagem histórico-cultural. Apontam que o uso de Libras como língua de instrução é fundamental para a construção de conceitos e para a aquisição de conhecimentos em leitura e escrita pelos alunos surdos em uma abordagem bilíngue, assim como didáticas apropriadas e embasadas em recursos imagéticos favorecem as trocas dialógicas, facilitando a compreensão pelos sujeitos surdos.

Leitura de imagens em arte: um olhar para a educação de surdos, é o título do artigo de Ivan Kappaun, Janete Müller, Daiane Kipper e Adriana Thoma, no qual os autores discutem a leitura de imagens por sujeitos surdos a partir de uma atividade escolar realizada com estudantes surdos que estudam em uma turma comum do Ensino Médio, em situação de inclusão. Articulando os Estudos Surdos com Arte-Educação, problematizam as possíveis implicações da experiência visual na educação escolar destes sujeitos. Desenvolvida na disciplina de Arte e mediada por tradutores e intérpretes de língua de sinais (TILS), a atividade oportunizou a aproximação dos alunos ao objeto imagético e seu contexto. Por fim, evidenciam um processo de leitura de imagens que toma como base a visualidade e as experiências singulares de cada sujeito na construção de significados.

Liliane Giordani, Daniele Noal Gai e Cássia Lobato Marins participam da edição com o artigo Cartografando currículos na educação de surdos: saberes e práticas docentes entrediferenças, no qual discutem a construção de um currículo na educação de surdos com deficiência a partir da análise de encontros de formação com professores e gestores em uma escola de surdos. Segundo elas, os encontros de formação produziram movimentos entre os professores e serviram para que fosse afirmada uma cultura visual bilíngue entre-diferenças. As autoras se propõem a pensar em construções coletivas para um currículo de aprendizagens, descrevendo ações que afirmam a escolarização e aprendizagem de alunos surdos com deficiência promovida em meio a uma cultura visual.

Corpo surdo e suas singularidades é o título do artigo de Aline Rodrigues, Angélica Munhoz e Morgana Hattge que tem por objetivo compreender os modos pelos quais alguns corpos surdos se singularizam e como potencializam suas vidas. Em meio a teorizações de 
filósofos da diferença, entre eles Deleuze e Barthes, perguntam: Como um corpo surdo é pungido por outras vias que não a representação? Para responder a isso, promovem encontros com três sujeitos surdos, a partir de trajetos percorridos com o uso da câmera fotográfica, que denominam de carto(foto)grafias. Em suas análises, apontam que a entrega do corpo é sempre algo difícil, de modo que fixa-se mais na objetividade e brevidade, do que naquilo que um corpo é capaz de produzir enquanto singularidade.

Liane Camatti e Márcia Lise Lunardi-Lazzarin são as autoras de Práticas de organização da comunidade surda: articulações a partir da cultura, artigo que tem por objetivo compreender como a comunidade surda se organiza e chega a ser entendida e narrada como um espaço de segurança no qual a diferença surda pode ser vivida com confiabilidade e acolhimento. Através de entrevistas com professores e alunos surdos, integrantes de escolas específicas para surdos e participantes ativos dos movimentos comunitários, realizam uma análise inspirada em estudos de vertente pós-estruturalista. Para elas, o pertencimento a uma comunidade implica vincular-se a um código de convívio (a lei da comunidade) que tem intencionalidades comuns e a referência que pauta a organização da comunidade surda está implicada em artefatos culturais do povo surdo. O quanto cada um pode ou deseja mover-se por tal lei é o que determina a relação de pertencimento de cada sujeito a essa comunidade, para além do sentimento de ser surdo e do compartilhamento de uma cultura.

$\mathrm{O}$ artigo Libras e Implante Coclear: Contradição e ou complementariedade, de Lilian Cristine Ribeiro Nascimento e Cibelle Carlos Sousa Lima, as autoras apresentam resultados de entrevistas realizadas com pais e mães de crianças surdas problematizando os motivos que os levaram a escolha simultânea de submeter seus filhos à cirurgia do Implante Coclear e à exposição à Língua Brasileira de Sinais. Inspirada especialmente em Foucault, a análise aponta para novas demandas e novas possibilidades educacionais para o sujeito surdo implantado bilíngue.

As crônicas de Jorge Sérgio L. Guimarães e as representações da surdez entre as décadas de 1950 e 1960, é o título do artigo de Tatiana Bolivar Lebedeff e Diogo de Souza Madeira. Os autores analisam e discutem textos publicados pelo escritor surdo Jorge Sérgio L. Guimarães entre as décadas de 50 e 60, publicados em forma de pequenas crônicas em três periódicos do Rio de Janeiro. Em 1961, os textos foram compilados no livro "Até onde o surdo vai". Para os autores, as crônicas analisadas apresentavam um discurso clínico e oralista sobre a surdez, típico daquele período. 
Fátima Sá Correia e Orquídea Coelho, autoras portuguesas, defendendo uma visão linguístico-cultural da surdez, apontam que as aulas de Filosofia em contexto de surdez colocam problemas específicos. A tradução de conceitos filosóficos para língua gestual (como é denominada a língua de sinais em Portugal) apresenta dificuldades particulares devido às características das duas línguas (língua vocal e língua gestual/língua de sinais). Além disso, nem todos os conceitos filosóficos possuem gesto standard em língua gestual portuguesa. As autoras apontam que as aulas de Filosofia devem ocorrerem em língua gestual portuguesa, tanto por um compromisso teórico como por imperativo legal daquele país. Assim, procuraram perceber de que modo esta língua resolve o problema da ausência de gesto, solicitando a um grupo de docentes surdas/os de língua gestual portuguesa que explicassem textos filosóficos nos quais estão presentes alguns desses conceitos. Por fim, analisaram essas produções gestuais com o intuito de extrair resultados elucidativos.

Em Matemática para a cidadania: discursos curriculares sobre educação matemática para surdos, de Bruna Alberton e Adriana Thoma, são analisados discursos que circulam nos Parâmetros Curriculares Nacionais (PCN/Mat) para o Ensino Fundamental e os Projetos Político-Pedagógicos (PPPs) de três escolas para surdos. Considerando os Estudos Foucaultianos, em especial a noção de discurso, são evidenciados e analisados discursos que tratam sobre cidadania e defendem que os sujeitos surdos precisam construir conhecimentos matemáticos para se constituir cidadãos participativos, críticos, justos e autônomos.

O futuro acadêmico e profissional nas representações sociais de jovens surdos do ensino médio é o artigo apresentado por Arlete Gonçalves, Ivany Nascimento e Huber Lobato, que tem por objetivo analisar as representações sociais de um grupo de jovens surdos moradores do arquipélago do Marajó, em especial, no que diz respeito ao futuro acadêmico e profissional. Nos resultados, o texto sublinha que os sujeitos surdos querem atuar na docência, possibilitando, com isto, que o seu trabalho contribua para que outros surdos conheçam a Língua Brasileira de Sinais - LIBRAS e a cultura surda.

Essa primeira seção encerra com o artigo Narrativas sobre a educação literária bilíngue na prática pedagógica com alunos surdos, de Lia Gurgel e Lodenir Karnopp. As autoras analisam uma prática pedagógica baseada em uma proposta de educação literária bilíngue, realizada em uma escola de surdos. O material empírico analisado foi produzido através do registro das atividades desenvolvidas no período da prática pedagógica. Como resultado, as autoras buscam evidenciar que a literatura articulada à proposta de ensino 
bilíngue contribui para estabelecer conexões entre línguas e culturas, bem como entre os conteúdos escolares propostos.

Além do dossiê, a edição conta com mais seis artigos. Inicia com Entre palavras $e$ vida: uma leitura sobre documentação pedagógica e narrativa no contexto da educação infantil inclusiva, de Luciane Simiano e Carla Vasques. Nele, as autoras discutem a documentação pedagógica como um percurso narrativo, produzido no contexto de uma experiência na educação infantil. A documentação analisada foi construída em conjunto com uma criança incluída, seus colegas e familiares e trata-se de um convite a inverter o olhar e pensar uma lógica que vê e narra a pequena criança e sua deficiência não como faltosa ou inábil, mas como força, potência e possibilidade.

Na sequencia, temos a contribuição de Jordi Planella, de Barcelona/Espanha. No texto Controversias socio-pedagógicas sobre la capacidad de ser sujeto: entre la dependencia y la autonomía, o autor propõe uma análise crítica de duas das categorias que operam nas teorias e práticas vinculadas a Pedagogia Social, seu campo de pesquisa. Planella analisa até que ponto a subjetividade pode promover a ideia de autonomia ou se, ao contrário, se pode sustentar uma interpretação da ideia de dependência, fazendo uma análise terminológica e pedagógica dos usos e abusos dos termos.

Educação Profissional, Trabalho e Produção de Saberes, de Maria Clarice de Oliveira e Naira Franzoi, apresenta um estudo de caso desenvolvido em uma escola técnica pública por dois estudantes trabalhadores, provenientes de uma região da indústria fumageira, no interior do Rio Grande do Sul. O foco é a forma como se deu o diálogo entre os saberes escolares, ou "constituídos" e os saberes experiências dos alunos. Os conceitos de atividade humana, trabalho, saberes e o Dispositivo Dinâmico de Três Polos (DD3P), na perspectiva da Ergologia, são a sustentação teórica do estudo. Assim,. As autoras buscam dar visibilizade a uma experiência bem sucedida em uma escola pública que tem como alunos jovens e adultos trabalhadores, explorando as possibilidades de uso de uma ferramenta teórico metodológica que objetiva promover o diálogo entre os saberes acadêmicos e os saberes engajados na atividade de trabalho.

No artigo As narrativas como recurso para o ensino de História, de Gusmão Amorim, Maria Rabelo e Jorge Rodriguez, os autores discutem o potencial das narrativas no ensino de história, destacando a narrativa histórica em sala de aula e seu diálogo com a narrativa literária. Para isso, utilizam princípios do método etnográfico como a observação, a descrição e a análise. A partir da narrativa oral de uma aula de História sobre a Primeira Guerra 
Mundial, produzida por uma professora para uma turma de terceiro ano do Ensino Médio, analisam e descrevem o enredo, o modo como se trabalhou com as personagens, o tempo e o espaço, o posicionamento do narrador e seu foco narrativo, procurando identificar que concepções de História se mostram na narrativa e como a estrutura e a função desses elementos permite a disseminação da cultura científica e a contextualização necessária à interpretação da história.

Apontamentos para construção da racionalidade ambiental é a contribuição de Munir Felício. Tais apontamentos foram propostos a partir de contribuições presentes nas análises da fenomenologia, da epistemologia e da ontologia do ser social em Marx, com o objetivo de ampliar e aprofundar a compreensão da problemática ambiental. $\mathrm{O}$ autor problematiza o desenvolvimento da racionalidade econômica a partir das degradações dos recursos naturais provocadas pelo atual avanço do modelo de desenvolvimento socioeconômico. Aponta que a interdisciplinaridade indicada pela epistemologia ambiental pode se tornar uma interessante estratégia de pesquisa, desde que tenha, como ponto de partida, as demandas externas onde se encontram os elementos da atual questão ambiental e de seus desdobramentos.

Por último, temos o artigo de Nelma Baldin e Amanda de Mello, intitulado Educação ambiental para sensibilizar a coparticipação com a natureza: a agroecologia na escola, que apresenta uma pesquisa inserida no Programa "Mais Educação" e que foi executada com 23 crianças do Ensino Fundamental de uma escola localizada na área rural de Joinville (SC). As autoras buscaram sensibilizar os alunos para a coparticipação com a natureza, visando à formação de agentes no cuidado com o meio ambiente, através de oficinas pedagógicas lúdicas e oficinas práticas que incentivaram o reaproveitamento e destinação correta dos resíduos e ações junto à terra. Segundo as autoras, as práticas pedagógicas e socioambientais estimularam a participação das crianças no contato com a natureza e com as questões da sustentabilidade ambiental.

Por fim, como o leitor poderá perceber, os artigos apresentam perspectivas e objetos analíticos diversos, se entrecruzando e instigando a aprofundamentos teórico-metodológicos em torno dos temas aqui apresentados.

Antes de finalizar gostaríamos de agradecer aos autores pela opção em publicar conosco e o grupo de pareceristas que propuseram correções, sugestões pertinentes, sempre considerando o viés teórico adotado pelo autor ou autores dos textos.

Desejamos uma boa leitura e que os textos sejam úteis aos professores e pesquisadores interessados nos temas reunidos nesse Dossiê. 


\section{REFERÊNCIAS}

FOUCAULT, Michel. História da Sexualidade Vol II: O uso dos prazeres. Trad. Maria Tereza da Costa Albulquerque. $8^{\circ}$ ed. Rio de Janeiro. Edições Graal, 1984.

LODI, Ana Cláudia Balieiro. Educação bilíngue para surdos e inclusão segundo a Política Nacional de Educação Especial e o Decreto n ${ }^{0}$ 5.626/05. In: Educação e Pesquisa, São Paulo, v.39, n.1, p.49-63, jan./mar. 2013.

LOPES, Maura Corcini ; THOMA, Adriana da Silva . Subjectivation, normalisation et constitution de l?éthos sourd: politiques publiques et paradoxes contemporains. La Nouvelle Revue de l'Adaptation et de la Scolarisation, v. 01, p. 105-116, 2013.

STURMER, Ingrid Ertel. ; THOMA, Adriana da Silva . Políticas educacionais e linguísticas para surdos: discursos que produzem a educação bilíngue no Brasil na atualidade. In: $37^{a}$ Reunião Anual da Anped, 2015, Florianópolis. Plano Nacional de Educação: tensões e perspectivas para a educação pública brasileira, 2015. p. 01-15.

THOMA, Adriana da Silva; KLEIN, Madalena. Experiências educacionais, movimentos e lutas surdas como condições de possibilidade para uma educação de surdos no Brasil. Cadernos de Educação, Pelotas, RS, n. 36, p. 107-131, maio/ago. 2010. 